\title{
Assessment of structural sediment connectivity within catchments: insights from graph theory
}

\author{
Étienne Cossart and Mathieu Fressard \\ Université de Lyon (Jean Moulin, Lyon 3), UMR 5600 CNRS - Environnement Ville Société, \\ Lyon, 69007, France \\ Correspondence to: Étienne Cossart (etienne.cossart@univ-lyon3.fr)
}

Received: 28 October 2016 - Discussion started: 8 November 2016

Revised: 24 March 2017 - Accepted: 28 March 2017 - Published: 10 May 2017

\begin{abstract}
To describe the sedimentary signal delivered at catchment outlets, many authors now refer to the concept of connectivity. In this framework, the sedimentary signal is seen as an emergent organization of local links and interactions. The challenge is thus to open the black boxes that remain within a sediment cascade, which requires both accurate geomorphic investigations in the field (reconstruction of sequences of geomorphic evolution, description of sediment pathways) and the development of tools dedicated to sediment cascade modeling. More precisely, the development of tools devoted to the study of connectivity in geomorphology is still in progress, although graph theory offers promising perspectives (Heckmann and Schwanghart, 2013). In this paper, graph theory is applied to abstract the network structure of sediment cascades, keeping only the nodes (sediment sources, sediment stores, outlet) and links (linkage by a transportation agent), represented as vertices and edges. From the description of the assemblages of sedimentary flows, we provide three main indices to explore how small-scale processes may result in significant broad-scale geomorphic patterns. The main hypothesis guiding this work is that the network structure dictates how sediment inputs from various sources interact at tributary junctions and finally at the outlet of a cascading system. First, we use the flow index to assess the potential contribution of each node to the sediment delivery at the outlet. Second, we measure the influence of each node regarding how it is accessible from both sediment sources and the outlet (using the Shimbel index). Third, we propose a new connectivity index named "Network Structural Connectivity index" (NSC) revealing whether the potential contribution of a node is lower or higher than expected from its location within the network. These indices are first computed for a conceptual sediment cascade network and then applied to a catchment located in the southern French Alps. We demonstrate that this index may be used to simulate sediment transfer and help in identifying the hotspots of geomorphic change. In the present case, we try to predict how a sediment cascade may be impacted by an edge disruption or a reconnection.
\end{abstract}

\section{Introduction}

The concept of connectivity now provides an overarching framework in geosciences to explore better how catchments function. Connectivity was first defined in ecology to assess the spatial coherence of a system of landscape elements, a coherence that is necessary to maintain or restore ecological functions (Bennett, 2004). Following these pioneering contributions, connectivity has been increasingly used by hydrologists to model hydrological connection patterns (Dela- haye et al., 2001; Douvinet et al., 2008). For instance, Ali and Roy (2009) stated that hydrological connectivity can be quantified as a function of the available water volume (calculated from a hydrological balance) and the rate of transfer. More recently, connectivity has appeared as a fruitful conceptual framework in geomorphology (Brierley et al., 2006; Wainwright et al., 2011; Fryirs, 2013; Hoffmann, 2015). It helps in studying the spatiotemporal unsteadiness of sediment transport within catchments and why sediment cascades can be considered a "jerky conveyor belt" (Ferguson, 
1981). Unsteadiness patterns in sediment transfers are indeed a major field of research for geomorphologists, and refer to the "spatial and temporal paradox" described by McGuiness et al. (1971): in a catchment, sediment delivery from sources on hillslopes is not correlated with sediment delivery at the outlet. Consequently, sediment cascades are not necessarily efficient in transferring sediments, highlighting a "sediment delivery problem" (Walling, 1983). Finally, geomorphic signals, especially sediment delivery, cannot be interpreted easily (e.g., in terms of climate change, anthropogenic influences) and may rather reveal a "sedimentological anarchy" (Walker, 1990; Bravard, 1998; Schumm, 2005). At the catchment scale, geomorphic processes may be alternately coupled to create a sediment impulse or may act to create a blockage.

Recently, many authors have sought a complex-systems approach to conceptualize the continuum of sediment transfer: how processes, at local scales, may be combined to understand the functioning of the whole sediment cascade (Fryirs et al., 2007; Borselli et al., 2008; Fryirs, 2013; Bracken et al., 2015). Such a multiscale framework was conceptualized by Heckmann and Schwanghart (2013), who clearly distinguished the coupling of processes and connectivity. On the one hand, geomorphic coupling is "the linkage of distinct landforms or landscape units by sediment transport" (Harvey, 2001); it refers to "elementary interactions at the relatively small scale" (Faulkner, 2008). On the other hand, "the degree of coupling, the combined effect of lateral (hillslope to channel) and longitudinal (from one river reach to another) linkages between system components, is termed (sediment) connectivity" (Heckmann and Schwanghart, 2013). Shifting from the local to the catchment scale remains the main issue in explaining how erosion and sediment transfer at small spatial scale interact and result in broad-scale geomorphic patterns and processes (Bracken et al., 2015). Addressing this issue requires the development of numerical methods to acquire an exhaustive inventory of all the local linkages within the sediment cascades, to assess their properties, and then to predict the result of their combination at catchment scale. One promising field of research has been opened up by the application of graph theory, which offers mathematical tools to analyze statistically the assemblages of all the components of a sediment cascade. It is a spatially explicit analysis since nodes and edges are spatial objects and since distance plays a role in the modeling (Heckmann and Schwanghart, 2013; Heckmann et al., 2015). This mathematical approach is based on a graph representation of the hydrological network that has been used for decades to describe watercourses shape and organization (Strahler, 1957; Chorley and Kennedy, 1971; Shreve, 1974). This methodological framework focuses particularly on structural connectivity, i.e., the influence of the spatial patterns formed by the linkages on sediment delivery. One main objective is to provide a quantitative index that would help in comparing the skeleton of the sediment cascades in both space and time. It could also be used to estimate the contribution of a given part of the catchment to provide sediment at the outlet and to predict where local erosion should be monitored (Cavalli et al., 2013).

In this paper, we propose a new connectivity index named "Network Structural Connectivity index" (NSC). Following a brief review of the literature on connectivity indices, we explore the main mathematical tools provided by graph theory to measure structural sediment connectivity. We particularly aim to complement the indices already published in order to develop a framework in which geomorphic simulations of changes can be carried out. The proposed connectivity index (NSC) is first described through a conceptual sediment cascade network (fictive and simple). Then, it is applied to the Celse-Nière study area (French Alps) to explore the spatial patterns of (dis)connectivity within the catchment based on a scenario analysis. Finally, we discuss the main applications and interpretations of the proposed connectivity index.

\section{State of the art}

By stating that catchments are inefficient at supplying sediment to the outlet, Walling (1983) pointed out a problem that arises from (dis)connectivity. He showed that catchments (especially larger ones) tend to be characterized by a low sediment delivery ratio (SDR) defined as

$\mathrm{SDR}=\frac{V_{\mathrm{o}}}{V_{\mathrm{h}}}$,

where $V_{\mathrm{o}}$ is the volume of sediment delivered at the outlet of the catchment and $V_{\mathrm{h}}$ is the volume of sediment eroded from hillslopes. The SDR is a synthetic index that provides a proxy to assess the connectivity of a catchment and allows comparisons in both space and time. Recently, it has been demonstrated that SDR (and connectivity) decreases with increasing landscape morphological complexity (Baartman et al., 2013). One main criticism regarding this index is that catchments remain a black box: no attention is paid to the geomorphic linkages present at the local scale, nor to the feedbacks among geomorphic processes (Gumiere et al., 2011; Viel, 2012; Fryirs, 2013). In this respect, the SDR has been interpreted as a simple "performance" factor to relate erosion measured at the plot scale to sediment yields observed at the larger scale. Its usefulness has been critically discussed (Hoffmann, 2015).

To open such black boxes, the concept of connectivity was subdivided into two distinct parts (With et al., 1997; Tischendorf and Fahrig, 2000; Turnbull et al., 2008). On the one hand, structural connectivity refers to spatial patterns in the landscape, such as the spatial distribution of landscape units, which influence sediment transfer patterns and sediment paths. On the other hand, functional connectivity focuses on how geomorphic processes may activate or block sediment transfer along the spatial links within the sediment cascade (Kimberly et al., 1997; With and King, 1997; 
Belisle, 2005; Uezu et al., 2005). The latter is also often called process-based sediment connectivity and was documented in depth in a recent review (Bracken et al., 2015). Here, we focus on structural connectivity, whose quantification is required to explore and understand the responses of geomorphic systems (Wainwright et al., 2011).

\subsection{Assessment of structural sediment connectivity}

Borselli et al. (2008) and Cavalli et al. (2013) developed a connectivity index (Eq. 2) that refers to structural connectivity. It estimates the connectivity at one location within the catchment as the ratio between an upslope (Eq. 3) and a downslope component (Eq. 4):

$$
\begin{aligned}
& \mathrm{IC}=\log _{10}\left(\frac{D_{\mathrm{up}}}{D_{\mathrm{dn}}}\right), \\
& D_{\mathrm{up}}=\bar{W} \bar{S} \sqrt{A}, \\
& D_{\mathrm{dn}}=\sum_{i} \frac{d_{i}}{W_{i} S_{i}},
\end{aligned}
$$

where $W$ is the average weighting factor of the upslope contributing area, $S$ is the average slope gradient of the upslope contributing area $\left(\mathrm{m} \mathrm{m}^{-1}\right), A$ is the upslope contributing area $\left(\mathrm{m}^{2}\right), d_{i}$ is the length of the flow path along the $i$ th cell according to the steepest downslope direction (m), and $W_{i}$ and $S_{i}$ are the weighting factor and the slope gradient of the $i$ th cell, respectively. In Borselli et al. (2008), the weighting factor $W$ corresponded to the $\mathrm{C}$ factor in the USLE-RUSLE models (Wischmeier and Smith, 1978; Renard et al., 1997), which represents friction hindering sediment transfer. More recently, it has been demonstrated that topographic surface roughness can provide a good estimation of the weighting factor (Cavalli et al., 2013; Baartman et al., 2013): a high roughness value is seen as impeding sediment transfer. This index opens up a fruitful field of research to assess structural connectivity. First, it opens the black boxes within a catchment: the IC can be calculated for each cell of the catchment, highlighting those cells that may efficiently route the sediment flux at the outlet. Second, this index takes into account all the links between a cell and all other components of the catchment, in agreement with the definition of connectivity. Third, the index can be mapped enabling comparisons between various locations (a specific tool has been developed in ArcGIS), and the calculation of maps of connectivity evolution over time (see, for example, case study applications in, among others, Foerster at al., 2014 and López-Vicente et al., 2016). Nevertheless, this index remains empirical and comparisons between catchments should be made carefully. More specifically, while such a method helps in identifying specific configurations that are highly susceptible to sediment delivery, it remains difficult to provide scenarios of change (e.g., the consequences of land use change, retention basin creation or removal).

\subsection{Graph theory applications to structural connectivity}

Another promising field of research is the application of graph theory, which provides a robust mathematical framework for describing networks such as sediment cascades (Heckmann and Schwanghart, 2013; Heckmann et al., 2015; Cossart, 2016). Graph theory is applied to model a network structure as nodes (representing sediment sources, sediment stores and the outlet) connected by edges (representing linkages by a geomorphological process).

Two nodes $i$ and $j$ are joined or adjacent if there is an edge from $i$ to $j$. A directed graph with $n$ nodes can be represented by an $n \times n$ adjacency matrix $\mathbf{A}$ and constructed as follows: if there is an edge from node $i$ to node $j$, then we enter 1 in row $i$, column $j$ of the matrix $\mathbf{A}$.

Both spatial and topological configurations of the network and the fluxes associated with the respective edges are responsible for the sediment delivery at the outlet (Heckmann and Schwanghart, 2013; Heckmann et al., 2015). The goal is thus to obtain a pattern that can be described by algebraic tools (typology of linkages, identification of local sinks, etc.) to show the overall structure of the sedimentary cascade. Graph theory enables an objective description of the connections of sedimentary flows, and thus an estimation of the potential influence of the network on the amount of sediment load. Indices provided by graph theory have been developed to describe the properties of single landscape units (nodes), sediment pathways (edges) and sediment cascades (edge sequences $=$ paths). The nodes can be characterized by the number and type of links that may provide or transport sediments. In graph theory, the so-called "source nodes" define nodes characterized by the absence of input links, sinks are characterized by no output link, and other nodes correspond to connectors whose importance is revealed by their degree (number of input and/or output links). It is important to note that the meaning of "source" differs from graph theory (node with no upstream contributor: starting points of the network) to geomorphology (node that can potentially supply sediments, which can be any node of the graph). The links may be characterized by the geomorphic process that carries sediments. Regarding the edge sequences, their main characteristic is whether or not they contribute to the sediment delivery at the outlet: do they correspond to an independent subcascade or not?

Another application is to carry out "flow analyses": in a directed graph (such as sediment cascades), each edge has a capacity and each edge is assigned a flow. A flow must satisfy the restriction that the amount of flow into a node equals the amount of flow out of it, unless it is a source, which has only an outgoing flow, or a sink, which has only an incoming flow. At each node, the sediments are supplied from the upstream flow and the potential local sediment delivery. The latter can be considered homogeneous on the whole catchment, or a potential sediment delivery map can be integrated to the simulation. This simulation is based on an assumption of flow 
conservation, and is a complementary approach to the assessment of sediment connectivity. In the case of sources with no incoming links, they can be assigned a default common value. The "network effect" (Pumain and Saint-Julien, 2010; Czuba and Foufoula-Georgiou, 2015) describes how the network structure may affect the "potential for creation, persistence, or dispersion of sediment waves" (Gran and Czuba, 2017) and finally the total delivery at the outlet (Czuba and Foufoula-Georgiou, 2015; Cossart, 2016).

Nevertheless, these indices do not predict the role of sediment connectivity on sediment delivery, especially in the case of scenarios of changes. New methodological procedures from graph theory need to be developed, so we propose here a brief description of the state of the art of previous studies in which the influence of a spatial network structure on material or immaterial fluxes has been thoroughly explored using graph theory. Although such studies have focused on geography (Cole and King, 1968; Gleyze, 2008), social networks (Freeman, 1979) or, more recently, ecology (Ludwig et al., 2002; Belisle, 2005), they have developed metrics and discussed concepts particularly relevant to geomorphology: the relationship between connectivity and the total amount of fluxes passing through the system, and the identification of local hotspots where any change may have an impact on the whole system (Marra et al., 2014; Czuba and FoufoulaGeorgiou, 2014, 2015; Masselink et al., 2017). In such studies, one key requirement is to provide a hierarchy of the influence of nodes within the network. Nodes characterized by high connectivity have a considerable influence within a network as they control the fluxes passing between many other nodes. Such high-connectivity nodes are also those where a disruption would lead to more serious damage of the network's functioning (Haggett and Chorley, 1969; Newman, 2010) and may be considered hotspots. They lie on the largest number of possible paths within the network. Many indices provided by graph theory have been applied to undirected graphs (for a review, see Rodrigue, 2017). Such indices are the result of a long procedure of research held by geographers to formalize spatial networks and spatial interactions (Pumain and Saint-Julien, 2010). From their experience we can avoid difficulties and understand how structural connectivity can be measured in directed graphs such as sediment cascades.

The betweenness centrality index $(B)$ measures the extent to which a node $i$ lies on paths between other nodes (Eq. 5):

$B_{i}=\frac{\sum n_{i j k}}{n_{j k}}$,

where $n_{i j k}$ is the number of paths that exist from a node $j$ to a node $k$ and that pass through $i$, and $n_{j k}$ is the total number of paths within the network, from $j$ to $k$. Such simulation provides a good evaluation of the potential volume that may pass through the nodes and is helpful in interpreting the real fluxes observed in each node of the network. One main criticism is that this index enhances the role of nodes close to the center of gravity of the network and is not especially efficient in ranking the influence of eccentric nodes (Rodrigue, 2017). However, such eccentric nodes are close to the sources of the network, so that they should be ranked in relation to their importance in sediment transfer. Furthermore, spatial patterns are taken into account in a simplistic way: the distance (and the friction effect associated to the distance to hinder fluxes) is not considered. We note that distance can be calculated in different ways: it can represent the length of the path, the time necessary to travel along the path, the cost necessary to travel, etc. Consequently, various properties of the edges can be used to approximate the velocity of sediment transfer (Czuba and Foufoula-Georgiu, 2015).

The Shimbel index (Shi) takes into account the distance between nodes and considers whether the location of the node increases or decreases the total length of all possible paths within the network (Eq. 6) (Newman, 2010; Rodrigue, 2017). For one node $i$, it corresponds to the sum of the length of all the shortest paths connecting all other nodes $j$ in the graph $\left(d_{i j}\right)$. To facilitate comparisons in both space and time, this index should be normalized, i.e., divided by the sum of the length of all the paths in the network, from $j$ to $k\left(d_{j k}\right)$ :

$\operatorname{Shi}_{i}=\frac{\sum d_{i j}}{\sum d_{j k}}$.

If the Shimbel index is high, then the node contributes to creating long paths within the network (and thus attenuates the compactness of the network). If the Shimbel index is low, then the node maximizes the compactness of the network. This index is much more efficient at ranking the influence of eccentric nodes on the network and can be enriched by considering various types of distance (geodesic, time, etc.). It is considered a very good proxy of accessibility and is thus sometimes called an "accessibility index". Nevertheless, we should point out that the lower the Shimbel index, the higher the accessibility (and thus the connectivity) of the nodes: while counterintuitive, this feature is now well accepted within the scientific community (Rodrigue, 2017).

Both indices enable an in-depth description of the skeleton of a network and highlight the potential impacts of the network structure on flux patterns. They can thus provide conceptual and mathematical frameworks to explore the structure of sediment cascades. Nevertheless, they cannot be applied directly to measure sediment connectivity as sediment cascades are directed graphs and thus more complicated in terms of mathematical conceptualization.

\section{Methodology: the Network Structural Connectivity index (NSC)}

From both recent developments on sediment connectivity metrics and past studies on the applications of graph theory to spatial networks, we now develop a methodological framework focusing on the analysis of sediment transfer within a 


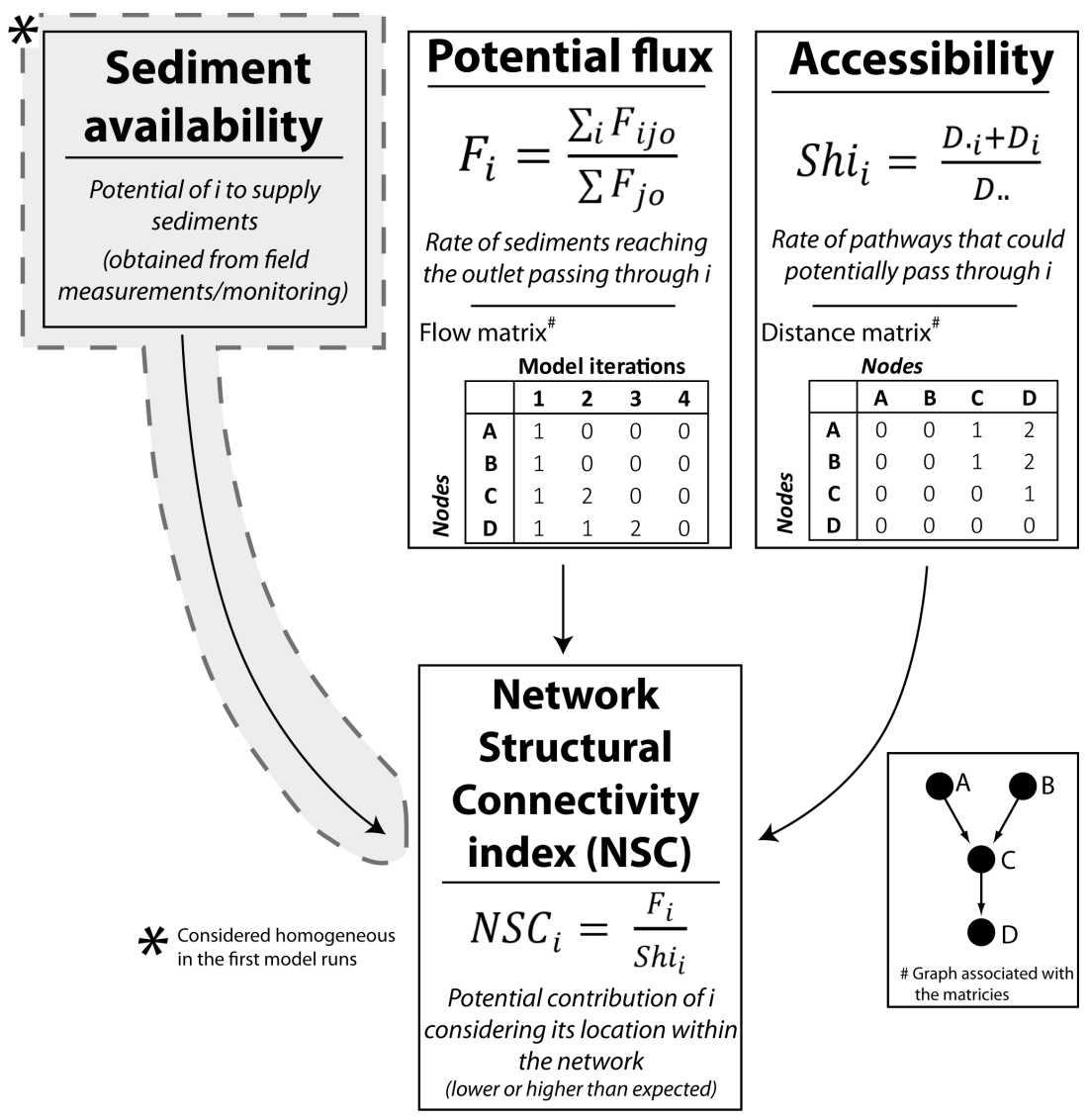

Figure 1. Overview of the main parameters used to build the network structural connectivity index (NSC) (equation details can be found in Sect. 3).

network. At the catchment scale, graph theory helps in identifying specific assemblages and, in particular, the subcascades that are not connected to each other. It corresponds to connected components, i.e., a subgraph in which nodes are all connected to each other (Newman, 2010). Their identification may reveal the spatial fragmentation of the sediment cascade and thus highlight the extent of the active contributing area in terms of sediment delivery at the outlet.

At a more local scale, to provide indices that can measure sediment connectivity within the sediment cascade, we have developed the NSC, which is based on (1) potential sediment fluxes and (2) accessibility (Fig. 1). The objective is to assess spatially the respective influence of each node on sediment connectivity inside the catchment area.

\subsection{Potential flows in directed graphs $(F)$}

As in undirected graphs, the first issue is to quantify the "network effect" (according to Pumain and Saint-Julien, 2010) to highlight how the spatial structure of paths influences the amount of sediment transferred to the outlet. In sediment cascades, only the paths that come from a node $j$ to the outlet $o$ have to be considered, so that, for each node $i$, we have to count the number of paths from $j$ to $o$ that include $i\left(F_{i j o}\right)$. This measurement is divided by the total number of paths that come from all nodes $j$ to $o\left(F_{j o}\right)$ to reveal the proportion of the total number of paths that lies on $i$ (Eq. 7):

$F_{i}=\frac{\sum_{i} F_{i j o}}{\sum F_{j o}}$.

$F_{i j o}$ and $F_{j o}$ can be calculated by reconstructing the sediment pathways throughout the cascade. Under the hypothesis of "all things being equal", a virtual volume of sediments ( 1 unit) is set on each node so that a spatially uniform sediment input is considered. As suggested by Gran and Czuba (2017) such a theoretical simplification allows the simulation of sediment wave generation and movement and exhibits the specific influence of the spatial structure of the network on the sediment wave pattern. In the case of converging flows, the progressive increase in the fluxes is exhibited. In the case of diverging flows, the flow can be subdivided between edges (equally or according to a weighting factor, e.g., slope gradient) so that the complex pattern of sediment wave generation and movement can also be described. In terms of mathematical procedure, the evacuation of sediment can be simulated by a multiplication of the adjacency matrix by 
a matrix representing the sediment variability $\left(\mathbf{S}_{n}\right)$ (Eq. 8). This is a one-column matrix, where each row represents a node of the cascade. In the initial conditions (first column, $\mathbf{S}_{0}$ ), a value of 1 is considered for each row to represent the virtual volume of sediments (one unit per node) at the beginning of the transfer. Each multiplication corresponds to an iteration, in which each sediment unit is transferred along one edge, according to the links described by the adjacency matrix (Eq. 8 and Fig. 1). The result provides a matrix $\mathbf{S}_{n}$, highlighting where the sediments are after one single iteration:

$\mathbf{S}_{n}=\mathbf{S}_{n-1} \times A$.

The operation is repeated until all the virtual sediments are evacuated, and the results can be represented within a synthetic matrix (S.), concatenating $\mathbf{S}_{0}, \mathbf{S}_{1}, \ldots, \mathbf{S}_{n}$ matrices, obtained during the calculation (Fig. 1).

\subsection{Accessibility from sources to sinks (Shi)}

Within a sediment cascade, the influence of geomorphic units (sources, stores, and sinks) on sediment delivery can be assessed by considering their location inside the cascades. A node whose centrality is high (i.e., characterized by a low summation of all distances between the other nodes and itself) has potentially greater influence on the overall sediment cascade. A first objective is to hierarchize the influence of nodes that correspond to confluences. In other words, if a strategic confluence is disconnected from the outlet (i.e., if an edge connecting the strategic node is disrupted) the spatial pattern of the transport capacity will be affected. Not only would the total amount of sediment fluxes change, but the "mutual interferences" that occur at such geomorphic hotspots would also be modified (Benda et al., 2004a, b). A second objective is to compare the potential influence of the network sources: the smaller the distance to the outlet, the greater the influence is.

Characterizing the nodes by their location within the network refers to the concept of accessibility and is thus very similar to the calculation of the Shimbel index in the case of undirected graphs. In directed graphs, the calculation of the accessibility (Shi) of each node $i$ can be made from a distance matrix $\mathbf{D}$ (Eq. 9 and Fig. 1):

$\overline{\operatorname{Shi}}_{i}=\frac{\mathbf{D}_{. i}+\mathbf{D}_{i .}}{\mathbf{D} . .}$,

where $\mathbf{D}_{.} i$ is the total of the distances between $i$ and the nodes (sources and stores) that feed $i, \mathbf{D}_{i}$. is the distance between $i$ and the nodes located downstream, and $\mathbf{D}$.. is the total of the distances of all the paths within the network.

\subsection{Combination of indices: NSC}

The indices $F$ and Shi provide a quantitative and complementary description of the cascade skeleton (e.g., both river network and hillslope processes): the first reveals the potential proportion of flux discharge passing through each node (e.g., water, sediments, and other types of constituents); the second measures the ratio of the length of paths that lie on $i$ (from all points within the catchment and to the outlet) and the total length of path within the network. Classically, the potential flux (e.g., sediment) discharge at a node increases in relation to the number of paths that come from sources (i.e., the active contributing area is larger; cf. the upslope component of Borselli's IC). Nevertheless, due to the geometry of paths, confluences and, more generally, the network structure, there can be some interference in terms of sediment movement through the system: the sediment discharge at a node can be higher or lower than expected from the single number of paths supplying sediments. To estimate this possible under- or overrepresentation of potential sediment volume at each node, a ratio between $F$ and Shi can be calculated (Eq. 10 and Fig. 1):

$\mathrm{NSC}_{i}=\frac{F_{i}}{\operatorname{Shi}_{i}}$.

The expected results can be considered a normalization of the potential sediment fluxes $F_{i}$.

\subsection{Implementation}

From a geomorphological map, a graph can be digitized in GIS software (QGIS), which consists of depicting a regular network of nodes. Each node can be characterized by the geomorphic unit to which it belongs, and the linkages between the nodes can be digitized from geomorphological expertise. The links correspond to directed fluxes, driven by gravity, and we only consider converging flow. To simplify the network structure, each node cannot have two output links. The "Network" QGIS tools can be used to generate the adjacency matrix (as an edge list matrix) and exported to R software. In the latter, the matrix can be converted into an origin-todestination matrix, and the distance matrix is automatically created (for simplicity, the distance between adjacent pairs of geomorphic units is unity and not the Euclidean distance) using the "igraph" package (Csardi and Nepusz, 2006). All calculations on matrices were conducted in $\mathrm{R}$, and the results were exported to QGIS to be mapped.

\section{Results and interpretation}

\subsection{Implementation on a virtual catchment}

To address the role of network structure in sediment fluxes, a conceptual sediment cascade network is first used as an example. The indices are calculated on a small virtual catchment of seven nodes and six links (Fig. 2a), from the adjacency matrix and the distance matrix (Tables 1 and 2). The first model run is parameterized in a simplistic way so that 
(a)

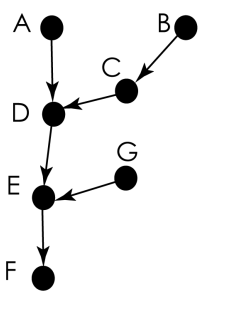

(b)

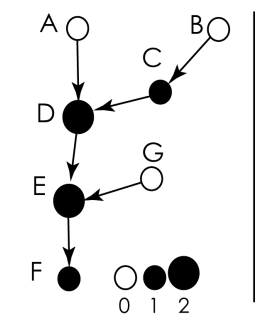

(C)

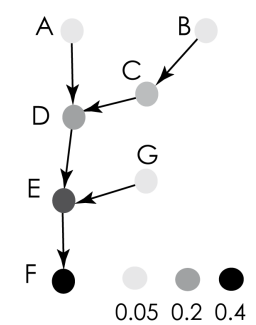

Figure 2. The virtual sediment cascade. (a) The structure of the cascade, represented by a graph; all nodes are supposed equals in terms of sediment availability (spatially uniform sediments availability; virtual units =1). (b) The potential flow of sediments after one iteration during the simulation (see also Table 3, column " 1 "); (c) map potential flux index $\left(F_{i}\right)$ values (see also Table 3 , column "F $F_{i}$ ").

Table 1. Adjacency matrix of the virtual sediment cascade.

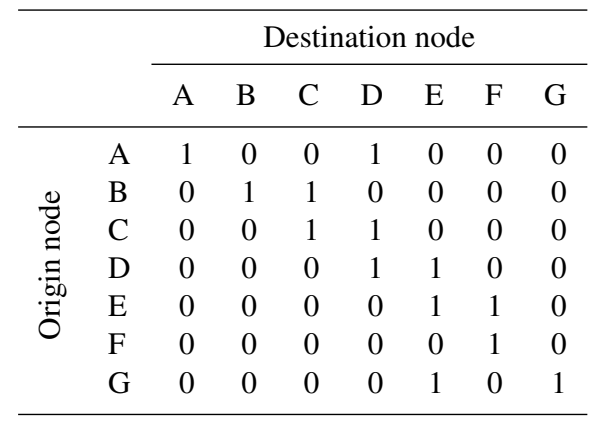

all sources are assumed to be of equal importance, using spatially uniform sediment inputs (volume availability equals 1 at each node at time 0 ) and a topological distance (each edge corresponds to a distance of 1 unit).

\subsubsection{Potential fluxes $(F)$}

First, a map of the potential fluxes $\left(F_{i}\right)$ within the sediment cascade can be drawn (Fig. $2 \mathrm{~b}$ and c, Table 3 ). Such a result can be useful for defining a local monitoring strategy (e.g., survey locations) for sediment transfer and then interpolating local measurements at the catchment scale. Moreover, the $F_{i}$ index may provide a hierarchy between the nodes by assessing the increase in sediment upstream and downstream of the node. For instance, in our virtual study case, the amount of sediment classically increases downstream, as there is no interruption of the cascade and we only consider converging flow. Nevertheless, the main increase occurs at node $\mathrm{D}$, pointing out that this node is a junction that receives input from various tributary systems. D may correspond to a zone of sediment persistence within the catchment, so that any disruption of this node (blockage due to sediment surplus that leads to aggradation, anthropogenic action, etc.) would significantly modify the development of the sediment pulse.
Table 2. Distance matrix (origin-to-destination) of the virtual sediment cascade. On the right, the rows detail the calculation of the accessibility index.

\begin{tabular}{|c|c|c|c|c|c|c|c|c|c|c|}
\hline & & \multicolumn{7}{|c|}{ Destination node } & \multirow[b]{2}{*}{$\mathbf{D}_{i}$} & \multirow[b]{2}{*}{ Shi $_{i}$} \\
\hline & & A & B & $\mathrm{C}$ & $\mathrm{D}$ & $\mathrm{E}$ & $\mathrm{F}$ & $\mathrm{G}$ & & \\
\hline \multirow{8}{*}{ 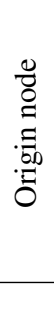 } & A & 0 & 0 & 0 & 1 & 2 & 3 & 0 & 6 & 0.21 \\
\hline & $\mathrm{B}$ & 0 & 0 & 1 & 2 & 3 & 4 & 0 & 10 & 0.35 \\
\hline & $\mathrm{C}$ & 0 & 0 & 0 & 1 & 2 & 3 & 0 & 6 & 0.24 \\
\hline & $\mathrm{D}$ & 0 & 0 & 0 & 0 & 1 & 2 & 0 & 3 & 0.24 \\
\hline & $\mathrm{E}$ & 0 & 0 & 0 & 0 & 0 & 1 & 0 & 1 & 0.35 \\
\hline & $\mathrm{F}$ & 0 & 0 & 0 & 0 & 0 & 0 & 0 & 0 & 0.52 \\
\hline & G & 0 & 0 & 0 & 0 & 1 & 2 & 0 & 3 & 0.10 \\
\hline & D. $i$ & 0 & 0 & 1 & 4 & 9 & 15 & 0 & 29 & \\
\hline
\end{tabular}

Table 3. Analysis of the potential sediment flow within the sediment cascade. The first rows correspond to the iterations simulating the evacuation of sediments. On the right, the rows detail the calculation of the flow index.

\begin{tabular}{|c|c|c|c|c|c|c|c|c|c|}
\hline & & \multicolumn{6}{|c|}{ Model iteration } & \multirow[b]{2}{*}{$F_{i j o}$} & \multirow[b]{2}{*}{$F_{i}$} \\
\hline & & 0 & 1 & 2 & 3 & 4 & 5 & & \\
\hline \multirow{7}{*}{$\begin{array}{l}\frac{0}{0} \\
\text { z }\end{array}$} & $\mathrm{A}$ & 1 & 0 & 0 & 0 & 0 & 0 & 1 & 0.05 \\
\hline & $\mathrm{B}$ & 1 & 0 & 0 & 0 & 0 & 0 & 1 & 0.05 \\
\hline & $\mathrm{C}$ & 1 & 1 & 0 & 0 & 0 & 0 & 2 & 0.09 \\
\hline & $\mathrm{D}$ & 1 & 2 & 1 & 0 & 0 & 0 & 4 & 0.18 \\
\hline & $\mathrm{E}$ & 1 & 2 & 2 & 1 & 0 & 0 & 6 & 0.27 \\
\hline & $\mathrm{F}$ & 1 & 1 & 2 & 2 & 1 & 0 & 7 & 0.32 \\
\hline & G & 1 & 0 & 0 & 0 & 0 & 0 & 1 & 0.05 \\
\hline \multicolumn{8}{|c|}{ Total } & 22 & \\
\hline
\end{tabular}

However, one main criticism is that the $F_{i}$ index pays little attention to the sediment sources (here A, B and G) (Fig. 2c). As the latter correspond to the initiation zones of the sediment cascade, the events that happen there may influence long pathways to the outlet. As mentioned for the betweenness index $(B)$, it is necessary to discriminate better the potential influence of sources and stores located next to sources.

\subsubsection{Accessibility (Shi)}

The accessibility (Shi) map can then be computed based on the distance matrix (Fig. 3 and Table 2). Here, $G$ is characterized by better accessibility, greater than both A and B: indeed the short distance between $\mathrm{G}$ and the outlet suggests it would have a higher influence on sediment delivery. From a geomorphic point of view, it reveals two distinct consequences without causal relation: first, the time of sediment transfer is short; second, the possibility of intermediate storage is low. Figure 3 thus illustrates such a hierarchy of the influence of sediment sources on sediment delivery at the outlet. In terms of management, it shows the sources that can be activated to 


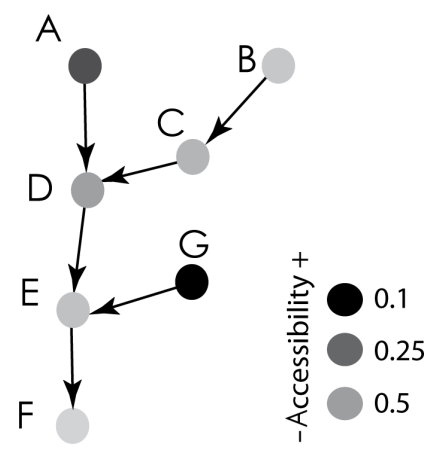

Figure 3. Assessment of the accessibility index (Shi) within the virtual sediment cascade.

cope with sediment exhaustion at the outlet or, conversely, sources where protection strategies should be applied in the case of sediment overflow. Because of this issue, this index is not a good proxy of connectivity as it underestimates the role of the outlet and all nodes close to the outlet, and does not pay attention to the confluences between various pathways inside the sediment cascade. At the catchment scale, the roles of D and $\mathrm{E}$ are not shown although they are important connectors between pathways developed from sources A and B. The indices of both nodes have to be carefully compared to note that $\mathrm{D}$ is closer to different sources and the outlet than $\mathrm{E}$.

\subsubsection{NSC}

The NSC provides synthetic metrics, suggesting that $\mathrm{E}$ and $\mathrm{D}$ are the most important geomorphic hotspots (Fig. 4), with very similar values ( 0.8 and 0.71 , respectively). $\mathrm{E}$ and $\mathrm{D}$ are at confluences and thus lie on various sediment paths from distinct sources. Their potential influence on the whole sediment cascade is high, so that any disruption of these nodes would considerably alter the elementary interactions between many nodes and sediment paths. Consequently, D and E may significantly modify the ability of the cascade to provide sediments and should be further studied in depth to document the functional connectivity or to assess erosional rates (local monitoring, field observations). The outlet $\mathrm{F}$ has quite a high index (0.66) but lower than E and D. This value highlights that the connectivity of a node is not proportional to the total volume of sediment that passes through it. In the case of F, the NSC is partly influenced by the high potential sediment volume that passes through it, but we point out that any disruption at this node would be ambiguous. For example, it would interrupt the sediment delivery but the organization of the three tributary subcascades from sources A, B and G would not be modified. Furthermore, the patterns of mutual interferences at the confluences (E and D) would also remain unmodified, so that sediment pulse generation and movement would not be modified. Consequently, the spatial structure of the cascade network would be roughly unchanged under the hypothesis of F disruption. Regarding the sources (A, B and

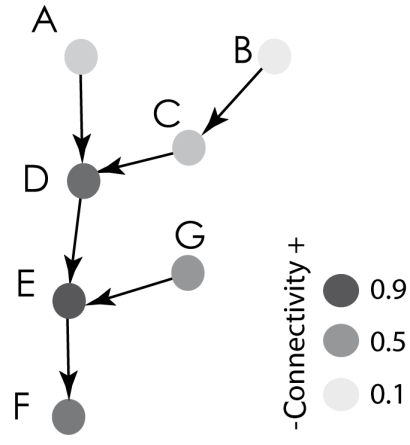

Figure 4. Assessment of the connectivity within the virtual sediment cascade using the NSC index.

D), a hierarchy is evidenced: the source $G$ has a greater influence on the sedimentary signal at the outlet due to its proximity ( $\mathrm{NSC}=0.53$ ), which is greater than A and B (NSC equals 0.27 and 0.12 , respectively).

\subsubsection{Sensitivity of NSC to sediment availability}

To investigate how sensitive the indices are to parameterization, we modify the initial conditions of our virtual sediment cascade. Regarding sediment availability, we consider $\mathrm{G}$ exhausted (volume equals 0 ) and B overflowing (volume equals 2). All other nodes remain unchanged. Regarding the distance between $\mathrm{E}$ and $\mathrm{F}$, it is now twice the initial value ( $D_{\mathrm{EF}}$ equals 2) (Fig. 5a and Table 4).

To interpret the result we first differentiate nodes whose connectivity increases and nodes whose connectivity decreases. As expected, the potential flow $F_{i}$ is mainly modified at $\mathrm{B}$, whose influence increases $\left(F_{\mathrm{B}}\right.$ shifts from 0.05 to 0.07 ), and at $\mathrm{G}$, whose influence becomes null (Fig. $5 \mathrm{~b}$ and Table 4). At other nodes, an increase is observed at $\mathrm{D}\left(F_{\mathrm{D}}\right.$ shifts from 0.18 to 0.21 ), while $F_{\mathrm{E}}$ and $F_{\mathrm{F}}$ remain roughly unchanged (shifting from 0.80 to 0.85 and 0.66 to 0.56 , respectively). While node D was already strategic in the first simulation, the increase in sediment availability at B reinforces its influence on the whole sediment cascade. Downstream, the potential flow at $\mathrm{E}$ and $\mathrm{F}$ is not reinforced by the amount of sediment delivered at $\mathrm{B}$ because of the exhaustion of G.

Considering the accessibility (Fig. 5c), the higher eccentricity of $\mathrm{F}$ has an impact on $\mathbf{A}_{\mathrm{F}}$ but, more generally, alters the accessibility of all nodes. The accessibility coefficient decreases significantly at B: the subcascade organized from B is the longest and all the sediment paths that may exist along this subcascade are impacted by the greater distance between $\mathrm{E}$ and $\mathrm{F}$. As a consequence, the outlet is here significantly less accessible from the source B than from the sources A and G (the latter remaining the closer). It can be noticed that the accessibility of $\mathrm{D}$ is not impacted by the higher eccentricity of F. $\mathbf{A}_{\mathrm{D}}$ remains roughly stable, and even suggests a slight improvement in accessibility. All nodes that are characterized 
(a)

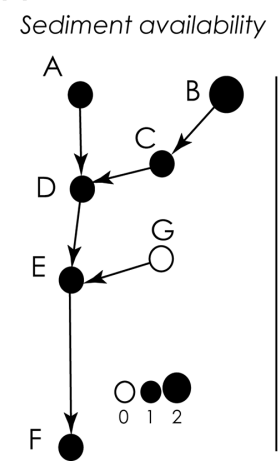

(b)

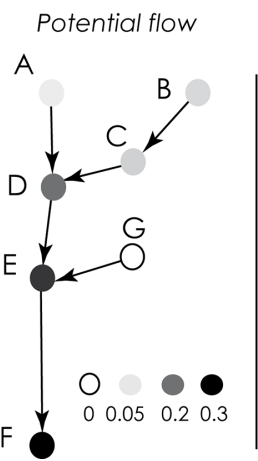

(c)

$$
\text { Accessibility }
$$

A

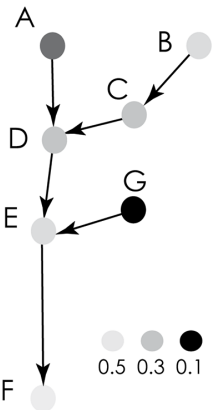

(d)

$$
\text { Connectivity }
$$

A

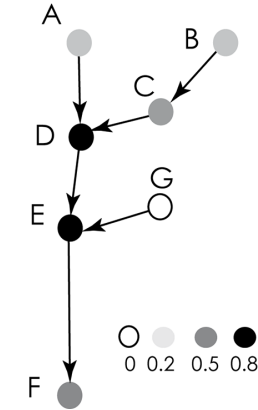

Figure 5. Flow, accessibility and connectivity indices following a modified parameterization. Note how the connectivity of node D is reinforced while the connectivity of $\mathrm{F}$ is reduced.

Table 4. Analysis of the potential flow and calculation of connectivity following a new parameterization. The rows indicate the patterns of sediment evacuation at each iteration of the simulation. Source B provides twice as many sediments and the distance between $\mathrm{E}$ and

\begin{tabular}{|c|c|c|c|c|c|c|c|c|c|c|c|}
\hline & & \multicolumn{6}{|c|}{ Model iteration } & \multirow[b]{2}{*}{$F_{i j o}$} & \multirow[b]{2}{*}{$F_{i}$} & \multirow[b]{2}{*}{$\operatorname{Shi}_{i}$} & \multirow[b]{2}{*}{$\mathrm{NSC}_{i}$} \\
\hline & & 0 & 1 & 2 & 3 & 4 & 5 & & & & \\
\hline \multirow{7}{*}{$\begin{array}{l}\frac{8}{0} \\
Z\end{array}$} & A & 1 & 0 & 0 & 0 & 0 & 0 & 1 & 0.03 & 0.18 & 0.20 \\
\hline & B & 2 & 0 & 0 & 0 & 0 & 0 & 2 & 0.07 & 0.35 & 0.20 \\
\hline & $\mathrm{C}$ & 1 & 2 & 0 & 0 & 0 & 0 & 3 & 0.10 & 0.28 & 0.38 \\
\hline & D & 1 & 2 & 3 & 0 & 0 & 0 & 6 & 0.21 & 0.25 & 0.83 \\
\hline & $\mathrm{E}$ & 1 & 2 & 2 & 3 & 0 & 0 & 8 & 0.28 & 0.33 & 0.85 \\
\hline & $\mathrm{F}$ & 1 & 1 & 2 & 2 & 3 & 0 & 9 & 0.31 & 0.55 & 0.56 \\
\hline & $\mathrm{G}$ & 0 & 0 & 0 & 0 & 0 & 0 & 0 & 0.00 & 0.08 & 0.00 \\
\hline
\end{tabular}
$\mathrm{F}$ is twice that during the initial conditions.

by great centrality, and that are closer to both the sources and the outlet, are not affected by an increasing eccentricity at the margins of the cascade (if the distance from sources, or to the outlet, increases).

Finally, regarding the connectivity index (Fig. 5d), the new parameterization modifies the hierarchy of nodes. First, the influence of the confluence nodes increases and, concomitantly, the influence of $\mathrm{F}$ decreases. As $\mathrm{F}$ is characterized by eccentricity, its influence on the overall system decreases. A disruption would modify the sediment cascade structure less (interplay at tributary junctions, organization of tributary subcascades) than in the previous model. D here appears as a node of high connectivity as it is close to two main sources and to the outlet. The node $\mathrm{E}$ is also of prime importance in terms of connectivity, but its NSC value is lower than expected from its strategic location. In fact, it is connected to an exhausted source $(G)$. Looking at the sources, a hierarchy is clearly observed: the influence of B increases due to its main contribution to the sediment flow, while the influence of $\mathrm{G}$ becomes null as it is exhausted.
The NSC thus reveals the degree of coupling to both the sources and the outlet for each unit of a sediment cascade. More precisely, it reflects the structural connectivity as it enhances the role of spatial patterns (distance, confluences, etc.) of the network. To make the interpretation easier, a high-connectivity node may modify the overall spatial network structure in the case of disruption (e.g., modifications of flux interplay at junctions, creation of independent sediment subcascades unconnected to the outlet). Moreover, the parameterization could be gradually enriched with geomorphic expertise to pay more attention to sediment availability or to the ability of geomorphic processes to transfer sediment along the paths (i.e., the edges).

\subsection{Application to a real sediment cascade}

The NSC is now applied to a real sediment cascade, whose functioning has already been conceptualized and quantified (Cossart and Fort, 2008; Cossart, 2016).

\subsubsection{The Celse-Nière catchment}

The Celse-Nière catchment is located in the French Southern Alps, on the eastern flank of the Massif des Écrins (Fig. 6). The current glaciation of this catchment is limited (about $6 \mathrm{~km}^{2}$ ), in spite of high altitudes (summit approaching $4000 \mathrm{~m}$ at Ailefroide), because this area is partly sheltered from oceanic influences due to its eastward location. For instance, precipitation is about $995 \mathrm{~mm} \mathrm{yr}^{-1}$ at Pelvoux $(1280 \mathrm{~m})$, which is significantly lower than on the western flank of the Massif des Écrins (1195 $\mathrm{mm} \mathrm{yr}^{-1}$ at Valjouffrey, $1160 \mathrm{~m}$ ). The equilibrium line altitude ranges from 3000 to $3200 \mathrm{~m}$ (Cossart, 2004), which is $200 \mathrm{~m}$ higher than in the western part of the massif.

We focus here on the headwater (about $10 \mathrm{~km}^{2}$, from 2500 to $3850 \mathrm{~m}$ a.s.1.), which is still occupied by glaciers. Some small tributaries converge into the upper part of the catchment (Ailefroide, Coup de Sabre) as their mouth is blocked by the Sélé valley glacier tongue. Such small catchments are 


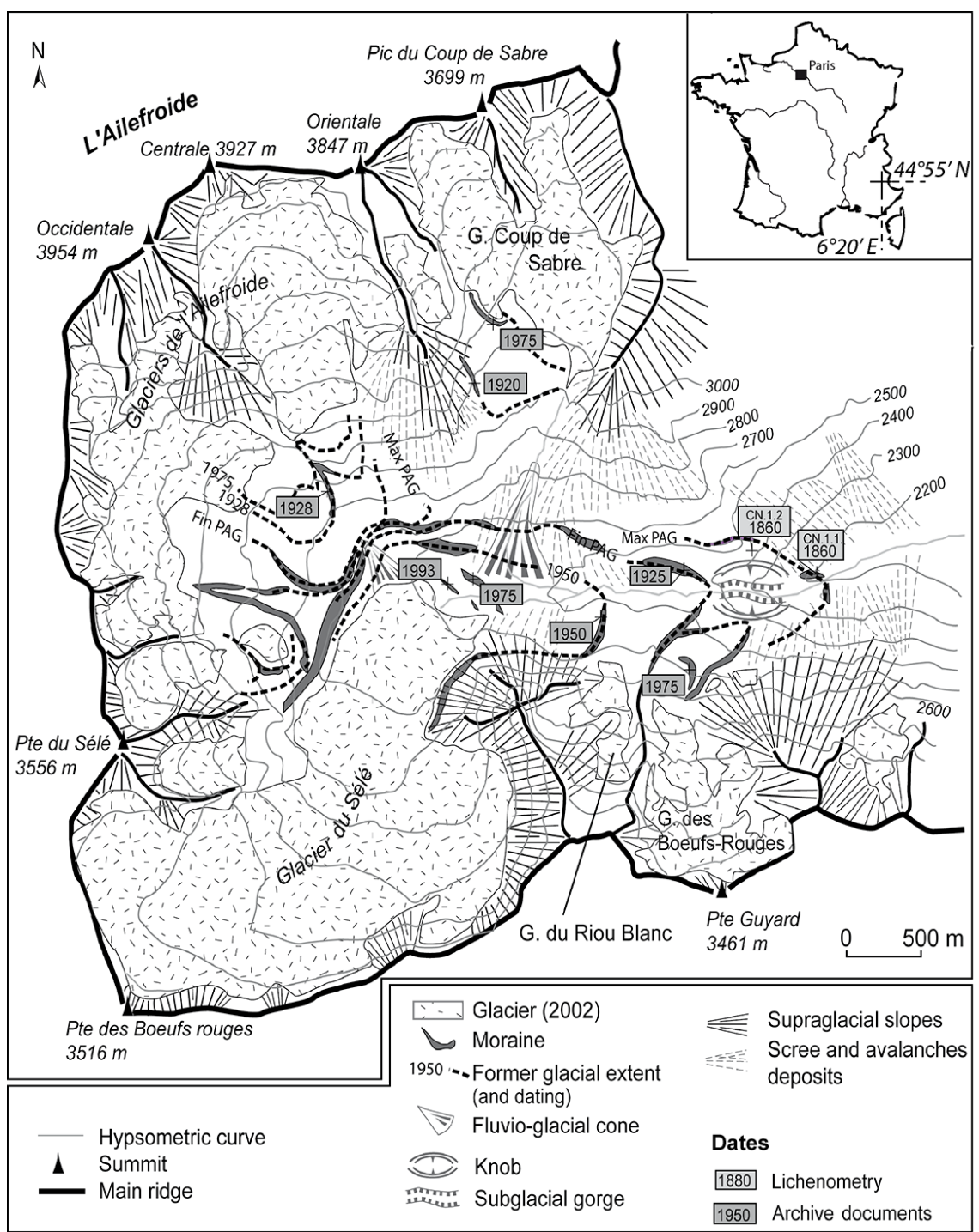

Figure 6. Geomorphological map of the study area: Celse-Nière catchment and sediment cascade.

occupied by cirque glaciers, which lie just below granitic and gneissic free faces and provide both sediments and meltwater to the valley floor. Special attention has already been given to the linkages between the glacial margins and the glacio-fluvial systems (Cossart, 2004, 2016). The presence of morainic ridges still interrupts the sedimentary cascade system, thus forcing local aggradation and change in the glaciofluvial pattern (Fig. 6). Such a complex assemblage makes this area particularly suitable for assessing connectivity and simulating the impacts of new blockages or, conversely, some reconnections.

\subsubsection{The structure of the network}

As in the virtual case study, a reduced-complexity network model is considered to address the role of the network's spatial structure (Fig. 7). The initial conditions of run 1 of the model are as follows: (1) sediment input (volume availability equals 1 at each node at time 0 ) is spatially uniform and (2) topological distance is considered (each edge corresponds to a distance of 1 unit).

First, it can be noticed that only $56 \%$ of all the paths are connected to the outlet, while the others are connected to permanent sinks. Twenty-five connected components are identified, highlighting a high fragmentation of the system: only 6 of these encompass more than 10 nodes (including the main connected component connected to the outlet) and 11 encompass fewer than 5 nodes. By applying the typology established by Fryirs et al. (2007), disconnections are due to barriers, buffers and blankets (Fig. 7a). Barriers are here mostly due to moraines: lateral moraines may affect the longitudinal coupling of processes, especially the coupling between glacio-fluvial streams from the cirque glaciers and 

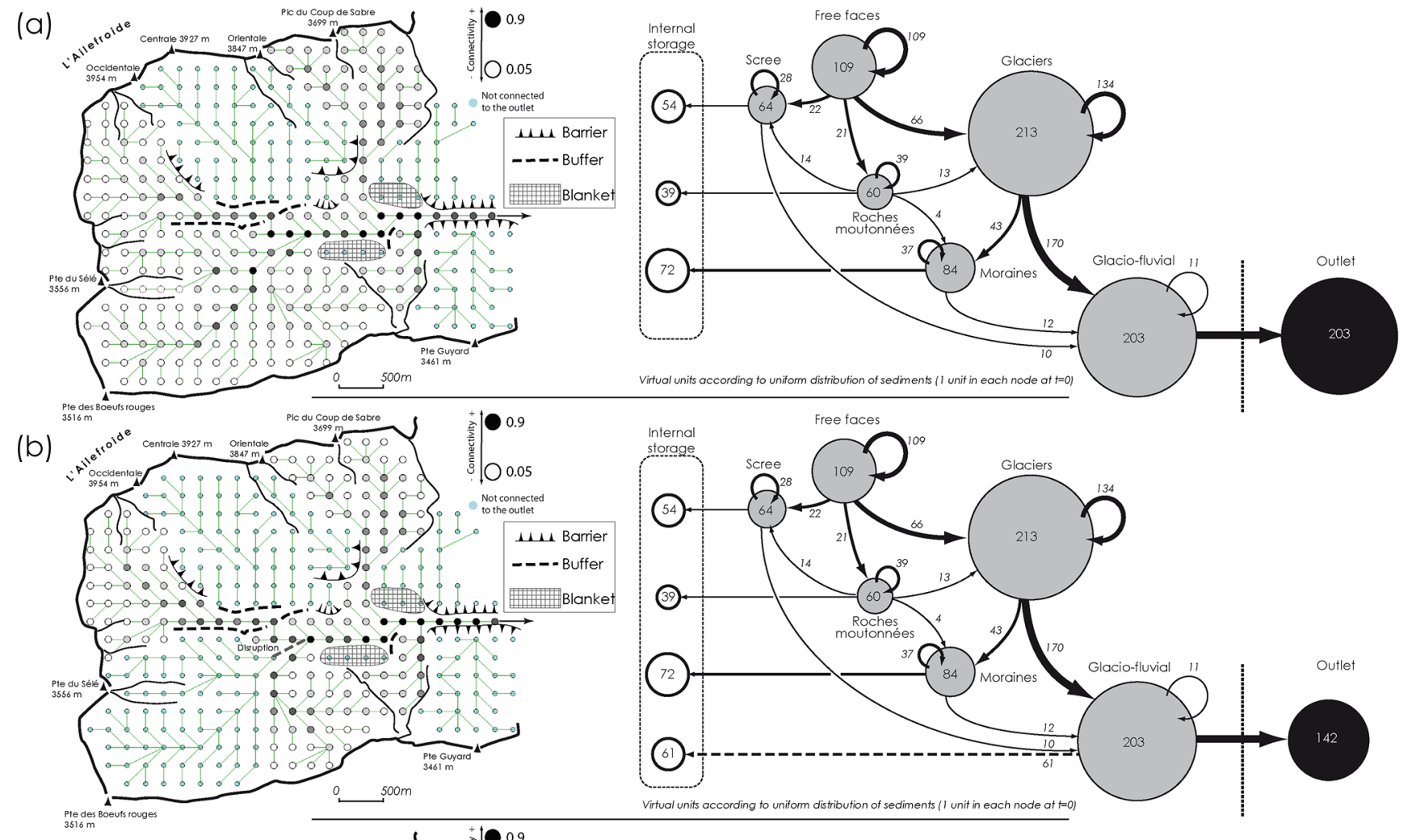

(c)
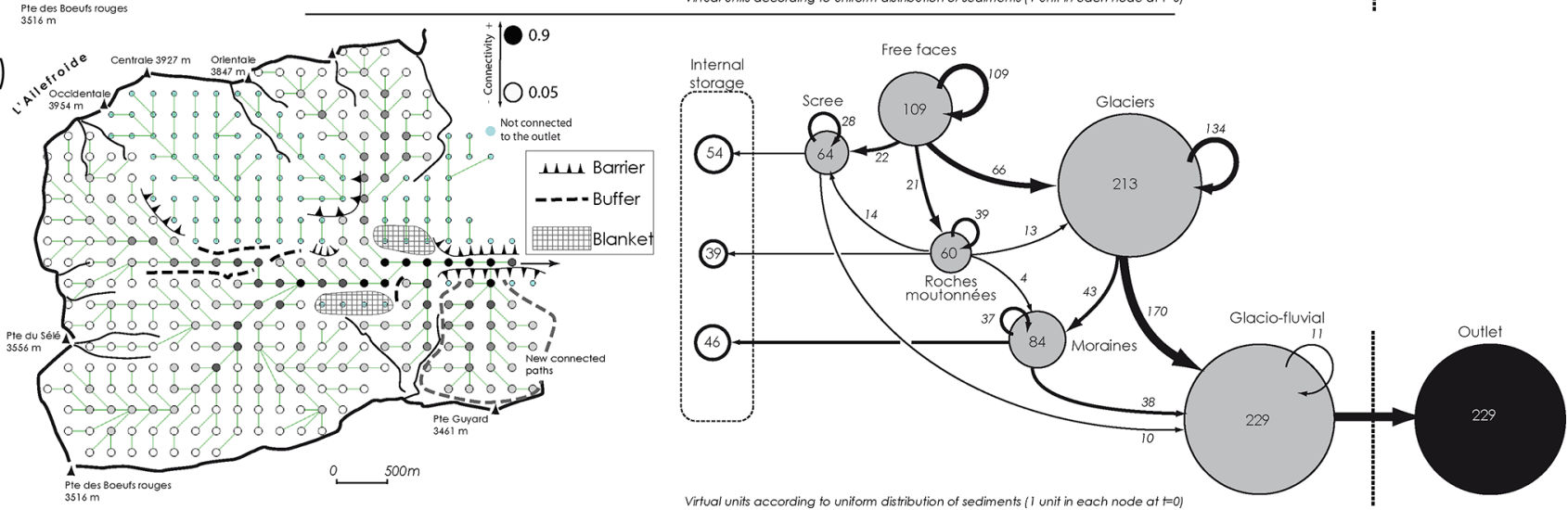

Figure 7. Assessment of connectivity. (a) Current structure of the cascade. (b) Connectivity map after the simulation of a disruption at Sélé toe. (c) Connectivity map after the simulation of a reconnection at Guyard outlet.

the mainstem. In that case, the node that corresponds to the upper part of the moraine is a sink, the node corresponding to the downslope part of the moraine is a source, but there is no link between these both nodes.

Buffers correspond not only to moraines, where they decouple scree deposits from the mainstem (scree deposition is forced by the morainic ridge), but also roches moutonnées and glacio-fluvial terraces. Blankets correspond to scree deposits made of large grain-size boulders that cannot be removed by fluvial processes. Second, the NSC highlights the influence of the trunk valley located between the margin of the Glacier-du-Sélé and the confluence with the Coup-deSabre proglacial river, where high-connectivity nodes are ob- served (Fig. 6a). This means that potential sediment fluxes are higher than expected from the active contributing areas upstream, so that the network may develop here zones of potential sediment persistence within the catchment. Furthermore, such nodes correspond to tributary junctions between the main subcascades of the system. Here the mutual interference may have an influence on the generation of sediment pulse, and thus on its evolution (transfer to the outlet), as well as on the tributary subcascades located upstream. Sediment persistence, an aggradation pattern in these zones, may generate a retrogressive aggradation that may modify the functioning of subcascades (e.g., decrease in sediment transfer along subcascades in the case of impoundment). For these 
reasons, such nodes can be considered hotspots of geomorphic change, which can propagate a perturbation along the whole cascade due to a geomorphic change and thus modify the overall functioning of the system. A significant input of sediments (due, for instance, to a hydro-meteorological event) in these areas would increase the sediment delivery at the outlet and may also alter the ability of tributaries to deliver sediments. The NSC also exhibits a hierarchy between the sources. As they are closer to the outlet, all the sources located in the Coup-de-Sabre subcatchment have a greater influence on sediment delivery than the sources located in the Ailefroide, Sélé or Bœufs-Rouges areas.

Thus, the map of the NSC helps to conceptualize the continuum of sediment transfer and to predict the downstream transfer and delivery of sediment fluxes measured at one point (not necessarily at the outlet). Node connectivity may need to be examined to establish sampling strategies for small-scale measurements of erosion in the field. Furthermore, this first examination highlights that the potential impacts of external drivers (anthropogenic impact, hydrometeorological event and, more generally, climate change) are space-dependent: the impacts may be greater and efficiently propagated if they affect high-connectivity areas.

\subsubsection{What if...?}

The connectivity hierarchy between nodes can be interpreted as the potential influence of the node on sediment delivery and the overall functioning of the cascade. The NSC and, more generally, tools provided by graph theory enable the simulation of scenarios to predict which events would have more impact on the cascade. We applied two other model scenarios in $\mathrm{R}$ to simulate the consequences of a local disconnection and a local reconnection. Run 2 corresponds to an algorithm that tests which edge removal would have the greatest impact on sediment connectivity (i.e., the largest decrease in connectivity at the node characterized by the highest connectivity) (Fig. 7b). This simulation could reflect the possible impact of an anthropogenic feature (e.g., a dam) or a hillslope process (e.g., a dam created by a landslide mass or a debris flow). Run 3 (Fig. 7c) corresponds to an algorithm that tests which creation of a new edge would lead to the greatest improvement in connectivity (i.e., where can we create the highest increase in the NSC value at a node?). This simulation could reflect the disruption of a barrier, the removal of a blanket or the overwhelming of a buffer, for instance following a high-magnitude geomorphic event.

Run 2 highlights that the greatest impact would occur if the edge located at the toe of the Glacier du Sélé was disrupted. It would lead to the disconnection from the outlet of the main subcascade (fed by Sélé sediment sources) so that only $40 \%$ of the nodes would remain connected to the outlet (compared to $56 \%$ in the initial stage). Nevertheless, the modification of the whole system is not just a question of sediment delivery at the outlet. First, we point out that it may

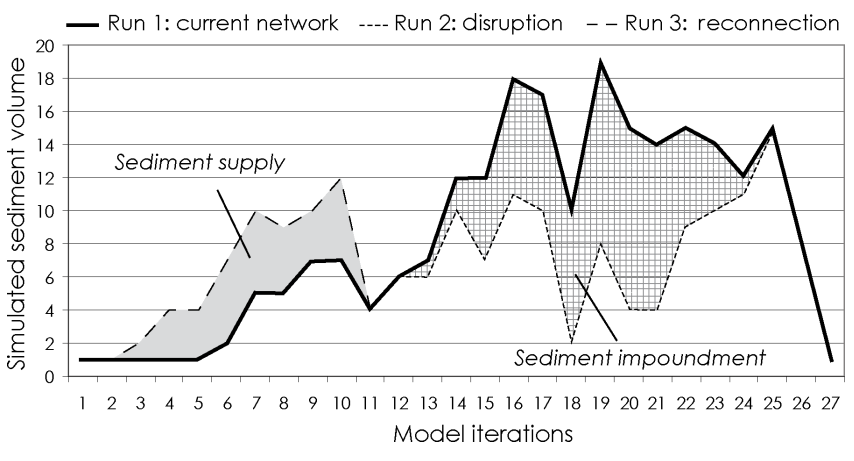

Figure 8. Sedimentographs associated with runs 1,2 and 3 on Celse-Nière catchment. Run 1 shows the current effect of the spatial network structure on sediment waves, run 2 the potential impact of an edge disruption in a hotspot zone, and run 3 the potential impact of a reconnection. Runs 1, 2 and 3 correspond to the graphs in Fig. 7a, b and c, respectively.

provoke an attenuation of the peak of the sediment wave if we compare the simulated sedimentographs between runs 1 and 2 (Fig. 8). Second, the disruption creates a subdivision of the sediment cascade connected to the outlet into two main connected components of quite similar size. The connected component that becomes disconnected from the outlet after run 1 (Bœufs-Rouges area) encompasses 72 nodes, and the other (still connected to the outlet) includes 142 nodes. Any other edge removal would lead to a new connected component of a smaller size ( $<72$ nodes). The disruption would be more significant than that of an edge located at the confluence with the Coup-de-Sabre proglacial river. In this latter case, many nodes would be disconnected from the outlet, but the three subcascades of Ailefroide, Sélé and Bœufs-Rouges would be less impacted and would still be self-organized within a large connected component. As a result, the structure of the sediment cascade would be less fragmented. Finally, the NSC shows where a local disruption may split two connected components of quite similar size, which may have a strong impact in terms of geomorphic functioning. As many geomorphic processes are scale-dependent, some variables influencing sediment transfer that are interdependent at one scale may well be independent at another (Schumm, 2005). A corollary is that the split of a cascade into two connected components (whose sizes are approximately half that of the initial cascade) may modify the scale at which geomorphic processes or controls act and markedly change the functioning of the system.

For run 3, a new edge is added to improve the overall sediment connectivity (Fig. 6c). In this case, a link between the Guyard subcatchment and the trunk valley would create the highest NSC value at the confluence. Such an increase is due to the large number of nodes (64\%) that would become connected to the outlet. Furthermore, these nodes (especially the sources) are relatively close to the outlet, so that the sediment wave exhibits an increase at the beginning of the pulsation 
(Fig. 8). A reconnection of the subcascade in the Ailefroide area would have a lesser impact because of its eccentricity. It can be noticed that the reconnection of the Guyard subcascade would decrease the influence of the Coup-de-Sabre subcascade on the overall network: in this scenario of reconnection, all the sources of this area are affected by a decrease in NSC. According to this new cascade structure, the hierarchy of sources would be modified: the sources of the Guyard area would have a greater influence than the Coup-de-Sabre sources, which would have a greater influence than the Ailefroide, Sélé and Bœufs-Rouges sources.

The NSC provides an exploration of the cascade structure and may explain to what extent a small-scale modification (disruption of a node, creation of a linkage) may result in significant changes in broad-scale geomorphic patterns and processes. In our examples, it can also predict the potential impacts on the sediment wave pattern (Fig. 8). More generally, the NSC enables comparisons between different states of connectivity within the same catchment.

\section{Discussion}

Several papers have already addressed the assessment of connectivity (Borselli et al., 2008; Cavalli et al., 2013; Czuba and Foufoula-Georgiu, 2015; Gran and Czuba, 2017; Hoffmann, 2015), so we focus here on the potential improvements offered by graph theory. Following Heckmann and Schwanghart (2013), a graph provides both a geometric and an algebraic description of the sediment cascade network. By identifying the connected components within the system, the examination of the geometry of the graph first helps to assess the SDR at the catchment scale and to identify the recurrent types of process coupling. In detail, it aims to determine the interaction of processes that are (in)efficient within the cascade at supplying sediments to the outlet. From the case studies developed here, we also highlight how an algebraic framework may help in exploring how the cascading system functions. Reduced-complexity network models associated with simple hypotheses (spatially uniform sediment inputs, simple assessment of the distance between nodes based on a topological distance) highlight the zones of greater sediment persistence, where sediment may accumulate in the network. Consequently, the role of the network's spatial structure in the generation of a sediment wave can be simulated and the associated sedimentograph can help in deciphering what is really due to external boundary conditions in sediment delivery variability at the outlet (Fryirs, 2017). Another result is the rank assessment of the geomorphic importance of the nodes, considering their location within the catchment. Following previous authors (Cavalli et al., 2013; Czuba and Foufoula-Georgiu, 2015; Gran and Czuba, 2017), the NSC identifies some specific zones that correspond to hotspots of geomorphic change due to their strategic location closer to the sources and the outlet. One main improvement in the graph theory framework is that geomorphic expertise can be integrated within algebraic formalization. First, sediment availability can be seen as $\mathbf{S}_{0}$ matrix. Second, the influence of barriers, buffers and blankets on network structure (connections and disconnections patterns) can be taken into account within the adjacency matrix. Furthermore, graph theory helps in developing simulation scenarios, while the associated algorithms show the properties of such geomorphic hotspots. Hotspots not only influence the total amount of sediment that is delivered at the outlet but also reveal where disconnections or reconnections may have a strong impact on the organization of the sediment cascade. A disconnection occurring at a hotspot may split the cascade into connected components of quite similar size, modifying the sedimentograph pattern, and may break the organization of path sequences.

Such a focus on the spatial dependence of geomorphic processes should be complemented, and the graph can be gradually enriched to take into account more complexity. A geomorphic hierarchy of nodes (in terms of sediment supply) can be parameterized: for instance, if a storage landform overflows or, conversely, is exhausted. The matrix representing the sediment sources can then be adjusted. Second, distance is an important parameter that can modify the results of $\mathrm{Ai}$, and thus NSC. Distance involves friction, which hampers the sediment transfer: the greater the distance, the higher the potential friction opposing sediment delivery (i.e., the transfer time increases). Many other kinds of distance can be taken into account, such as the Euclidian distance, but in geomorphology other types of distance may be more relevant. For example, a distance expressed as a time, to reveal the "virtual velocity" of sediment transfer from one unit to another, can be particularly appropriate, although difficult to assess. A cost distance can also be relevant. By revealing how hampered (or efficient) the sediment transfer is along the edge, a Manning coefficient, or more generally a roughness index (Broselli et al., 2008; Cavalli et al., 2013; Baartman et al., 2013), can be a good proxy of the friction that hampers the sediment transfer. Such parameters can be calculated from high-resolution digital elevation models, combined with the edge characteristics through GIS procedures, and finally integrated within the matrices necessary for the calculations. In this way, graph theory provides a methodological framework that can be extensively enriched by various parameters to reveal the transport capacity, and consequently the potential interplay between network geometry and spatial patterns of transport. One perspective of research is to complement this approach with a more dynamic modeling of the sediment cascade network structure. It is well known that the assemblages of links and nodes may evolve in accordance with various external forces (e.g., climate, human practices, tectonics). For instance, agent-based models can be suitable to predict the possible evolution of the structure by considering negative and/or positive feedbacks along the edges (Reulier et al., 2016). 


\section{Conclusion}

This paper seeks to develop an original methodology dedicated to the study of sedimentary cascades under the hypothesis that the influence of connectors and paths on sediment delivery is space-dependent. The methods rely on graph theory to assess structural connectivity: the sediment cascade is described as a network and consequently as a graph. Inspired by indices developed in other disciplines (transportation science, sociology, ecology), a potential flow and an accessibility of geomorphic units (i.e., accessibility to sediment sources and to the outlet) can be measured throughout the sediment cascade. Both indices are combined to estimate a connectivity index, which reveals how influential a node is within a sediment cascade. Specific applications were implemented in GIS software (QGIS) as well as in software dedicated to data analysis and matrix calculations (R).

The application on a simple virtual catchment and then on a real catchment shows how the network spatial structure may lead (or not) to sediment mobilization and exportation, from the upper slopes to the outlet of watersheds. The behavior of sediment cascades appears space-dependent: the geometry of paths and the location of nodes have a direct influence on structural connectivity and thus on the ability of the sediment cascade to deliver sediments. As a consequence, some hotspots of geomorphic change can be identified within the catchment. The impact of an external force on the sediment cascade depends on the location of its action: the higher the connectivity of the node, the higher the impact on the cascade. Moreover, some simulations can be conducted to predict how local perturbations may have an impact on the overall cascade.

This issue (characterizing sediment connectivity at the catchment scale) is one of the main challenges in geomorphology and may help in understanding how a sediment wave develops and moves downstream. In detail, it may be possible to decipher better whether sediment pulses reveal the spatial network structure or external boundary conditions (e.g., climate change, anthropogenic pressure, tectonics). Such results are of importance for management issues, for instance in the discussion of the location of a retention basin for sediments in a context of severe erosion, or where sediment continuity should be restored to cope with sediment exhaustion in some rivers.

Data availability. The raw data and modeling $\mathrm{R}$ code are accessible by direct request to the corresponding author.

Competing interests. The authors declare that they have no conflict of interest.
Acknowledgements. The authors acknowledge with thanks the anonymous reviewers for their fruitful comments that significantly improved the quality of the manuscript.

Edited by: P. Passalacqua

Reviewed by: two anonymous referees

\section{References}

Ali, G. V. and Roy, A. G.: Revisiting hydrologic sampling strategies for an accurate assessment of hydrologic connectivity in humid temperate systems, Geography Compass, 3, 350-374, 2009.

Baartman, J. E. M., Masselink, R., Keesstra, S. D., and Temme, A. J. A. M.: Linking landscape morphological complexity and sediment connectivity, Earth Surf. Proc. Land., 38, 1457-1471, 2013.

Belisle, M.: Measuring landscape connectivity: the challenge of behavioural landscape ecology, Ecology, 86, 1988-1995, 2005.

Benda, L. E. E., Andras, K., Miller, D., and Bigelow, P.: Confluence effects in rivers: interactions of basin scale, network geometry, and disturbance regimes, Water Resour. Res., 40, 1-15, 2004a.

Benda, L. E. E., Poff, N. L., Miller, D., Dunne, T., Reeves, G., Pess, G., and Pollock, M.: The network dynamics hypothesis: how channel networks structure riverine habitats, BioScience, 54, 413-427, 2004b.

Bennett, G.: Integrating biodiversity conservation and sustainable use. Lessons learned from ecological networks, World Conservation Union (IUCN), Gland, Switzerland, 2004.

Borselli, L., Cassi, P., and Torri, D.: Prolegomena to sediment and flow connectivity in the landscape: a GIS and field numerical assessment, Catena, 75, 268-277, 2008.

Bracken, L. J., Turnbull, J., Wainwright, J., and Bogaart, P.: Sediment connectivity: a framework for understanding sediment transfer at multiple scales, Earth Surf. Proc. Land., 40, 177-188, 2015.

Bravard, J. P.: Le temps et l'espace dans les systèmes fluviaux, deux dimensions spécifiques de l'approche géomorphologique, Ann. Géogr., 107, 3-15, 1998.

Brierley, G., Fryirs, K., and Jain, V.: Landscape connectivity: the geographic basis of geomorphic applications, Area, 38, 165-174, 2006.

Cavalli, M., Trevisani, S., Comiti, F., and Marchi, L.: Geomorphometric assessment of spatial sediment connectivity in small Alpine catchments, Geomorphology, 188, 31-41, 2013.

Chorley, R. J. and Kennedy, B. A.: Physical Geography: A Systems Approach, Prentice-Hall International, London, UK, 370 pp., 1971.

Cole, J. P. and King, C. A. M.: Quantitative Geography: Techniques and theories in geography, Wiley, New York, USA, 471 pp., 1968.

Cossart, É.: La recrudescence de l'activité torrentielle dans un bassin versant en cours de déglaciation au cours du XXe siècle, Géomorphologie, 3, 225-240, 2004.

Cossart, É.: L'(in)efficacité géomorphologique des cascades sédimentaires en question: les apports d'une analyse réseau, Cybergeo: European Journal of Geography [Online], document 778, doi:10.4000/cybergeo.27625, 2016.

Cossart, É. and Fort, M.: Sediment release and storage in early deglaciated areas: Towards an application of the exhaustion 
model from the case of Massif des Écrins French Alps since the Little Ice Age, Norsk Geogr. Tidsskr., 62, 115-131, 2008.

Csardi, G. and Nepusz, T.: The igraph software package for complex network research, InterJournal. Complex Systems, 1695, 19, 2006.

Czuba, J. A. and Foufoula-Georgiou, E.: A network-based framework for identifying potential synchronizations and amplifications of sediment delivery in river basins, Water Resour. Res., 50, 3826-3851, 2014.

Czuba, J. A. and Foufoula-Georgiou, E.: Dynamic connectivity in a fluvial network for identifying hotspots of geomorphic change, Water Resour. Res., 51, 1401-1421, 2015.

Delahaye, D., Guermond, Y., and Langlois, P.: Spatial interaction in the run-off process, Cybergeo: European Journal of Geography [Online], document 213, doi:10.4000/cybergeo.3795, 2001.

Douvinet, J., Delahaye, D., and Langlois, P.: Modélisation de la dynamique potentielle d'un bassin versant et mesure de son efficacité structurelle, Cybergeo: European Journal of Geography [Online], document 412, doi:10.4000/cybergeo.16103, 2008.

Faulkner, H.: Connectivity as a crucial determinant of badland geomorphology and evolution, Geomorphology, 100, 91-103, 2008.

Ferguson, R. I.: Channel forms and channel changes, in: British Rivers, edited by: Lewin, J., Allen and Unwin, London, UK, 90125, 1981.

Foerster, S., Wilczok, C., Brosinsky, A., and Segl, K.: Assessment of sediment connectivity from vegetation cover and topography using remotely sensed data in a dryland catchment in the Spanish Pyrenees, J. Soils Sediments, 14, 1982-2000, 2014.

Freeman, L. C.: Centrality in social networks conceptual clarification, Soc. Networks, 1, 215-239, 1979.

Fryirs, K.: DisConnectivity in catchment sediment cascades: a fresh look at the sediment delivery problem, Earth Surf. Proc. Land., 38, 30-46, 2013.

Fryirs, K., Brierley, G. J., Preston, N. J., and Kasai, M.: The disconnectivity of catchment-scale sediment cascades, Catena, 70, 49-67, 2007.

Fryirs, K. A.: River sensitivity: A lost foundation concept in fluvial geomorphology, Earth Surf. Proc. Land., 42, 55-70, 2017.

Gleyze, J. F.: Effets spatiaux et effets réseau dans l'évaluation d'indicateurs sur les nœuds d'un réseau d'infrastructure, Cybergeo: European Journal of Geography [Online], document 370, doi:10.4000/cybergeo.5532, 2008.

Gran, K. B. and Czuba, J. A.: Sediment pulse evolution and the role of network structure, Geomorphology, 277, 17-30, 2017.

Gumiere, S. J., Le Bissonnais, Y., Raclot, D., and Cheviron, B.: Vegetated filter effects on sedimentological connectivity of agricultural catchments in erosion modelling: a review, Earth Surf. Proc. Land., 36, 3-19, 2011.

Haggett, P. and Chorley, R. J.: Network analysis in geography, edited by: Arnold, E., Science, London, UK, 348 pp., 1969.

Harvey, A. M.: Coupling between hillslopes and channels in upland fluvial systems: implications for landscape sensitivity, illustrated from the Howgill Fells, northwest England, Catena, 42, 225-250, 2001.

Heckmann, T. and Schwanghart, W.: Geomorphic coupling and sediment connectivity in an alpine catchment - exploring sediment cascades using graph theory, Geomorphology, 182, 89-103, 2013.
Heckmann, T., Schwanghart, W., and Phillips, J. D.: Graph theory: Recent developments of its application in geomorphology, Geomorphology, 243, 130-146, 2015.

Hoffmann, T.: Sediment residence time and connectivity in nonequilibrium and transient geomorphic systems, Earth Sci. Rev., 150, 609-627, 2015.

Kimberly, A. W., Gardner, R. H., and Turner, M. G.: Landscape connectivity and population distributions in heterogeneous environments, Oikos, 78, 151-169, 1997.

López-Vicente, M., Nadal-Romero, E., and Cammeraat, E. L.: Hydrological connectivity does change over 70 years of abandonment and afforestation in the Spanish pyrenees, Land Degrad. Dev., doi:10.1002/ldr.2531, 2016.

Ludwig, J. A., Eager, R. W., Bastin, G. N., Chewings, V. H., and Liedloff, A. C.: A leakiness index for assessing landscape function using remote sensing, Landscape Ecol., 17, 157-171, 2002.

Marra, W. A., Kleinhans, M. G., and Addink, E. A.: Network concepts to describe channel importance and change in multichannel systems: test results for the Jamuna River, Bangladesh, Earth Surf. Proc. Land., 39, 766-778, 2014.

Masselink, R. J., Heckmann, T., Temme, A. J., Anders, N. S., Gooren, H., and Keesstra, S. D.: A network theory approach for a better understanding of overland flow connectivity, Hydrol. Process., 31, 207-220, 2017.

McGuinness, J. L., Harrold, L. L., and Edwards, W. M.: Relation of rainfall energy streamflow to sediment yield from small and large watersheds, J. Soil Water Conserv., 26, 233-235, 1971.

Newman, M. E. J.: Networks: An Introduction, Oxford University Press, Oxford, UK, 2010.

Pumain, D. and Saint-Julien, T.: Analyse spatiale: les localisations, Cursus, Armand Colin, Paris, France, 192 pp., 2010.

Renard, K., Foster, G. R., Weessies, G. A., McCool, D. K., and Yodler, D. C.: Predicting soil erosion by water: a guide to conservation planning with the Revised Universal Soil Loss Equation (RUSLE), U.S. Department of Agriculture, Washington, USA, Agriculture Handbook, 703, 1-384, 1997.

Reulier, R., Delahaye, D., Caillault, S., Viel, V., Douvinet, J., and Bensaid, A.: Mesurer l'impact des entités linéaires paysagères sur les dynamiques spatiales du ruissellement: une approche par simulation multi-agents. Cybergéo. European Journal of Geography [Online], Systèmes, Modélisation, Géostatistiques, document 788, doi:10.4000/cybergeo.27768, 2016.

Rodrigue, J. P.: Geography of transport system, Routledge, New York, USA, 441 pp., 2017.

Schumm, S.: River variability and complexity, Cambridge University Press, Cambridge, UK, 219 pp., 2005.

Shreve, R. L.: Variation of mainstream length with basin area in river networks, Water Resour. Res., 10, 1167-1177, 1974.

Strahler, A. N.: Quantitative analysis of watershed geomorphology, EOS, Trans. Am. Geophys. Union, 38, 913-920, 1957.

Tischendorf, L. and Fahrig, L.: How should we measure landscape connectivity?, Landscape Ecol., 15, 633-641, 2000.

Turnbull, L., Wainwright, J., and Brazier, R. E.: A conceptual framework for understanding semi-arid land degradation: ecohydrological interactions across multiple-space and time scales, Ecohydrology, 1, 23-34, 2008.

Uezu, A., Metzger, J. P., and Vielliard, J. M. E.: Effects of structural and functional connectivity and patch size on the abundance of 
seven Atlantic forest bird species, Biol. Conserv., 123, 507-519, 2005.

Viel, V.: Analyse spatiale et temporelle des transferts sédimentaires dans les hydrosystèmes normands. Exemple du bassin versant de la Seulles, PhD Thesis, Université de Caen, France, 382 pp., 2012.

Wainwright, J., Turnbull, L., Ibrahim, T. G., Lexartza-Artza, I., Thornton, S. F., and Brazier, R. E.: Linking environmental regimes, space and time: interpretations of structural and functional connectivity, Geomorphology, 126, 387-404, 2011.

Walker, R. G.: Perspective, facies modelling and sequence stratigraphy, J. Sediment. Petrol., 60, 777-786, 1990.
Walling, D. E.: The sediment delivery problem, Hydrology, 69, 209-237, 1983.

Wischmeier, W. H. and Smith, D. D.: Predicting Rainfall Erosion Losses - A Guide to Conservation Planning, U.S. Department of Agriculture, Washington, USA, Agriculture Handbook, 537, $1-58,1978$.

With, K. A. and King, A. W.: The use and misuse of neutral landscape models in ecology, Oikos, 79, 219-229, 1997.

With, K. A., Gardner, R. H., and Turner, M. G.: Landscape connectivity and population distributions in heterogeneous environments, Oikos, 78, 151-169, 1997. 